\title{
Fenton Stability of Mesoporous Ceria-Silica and Its Role in Enhanced Durability of Poly(arylene ether sulfone) Multiblock Copolymer Composite Membranes for Perfluorosulfonic Acid Alternatives
}

Joonseok Kim, Hyejin Lee, Eun-Bum Cho,* and Byungchan Bae*

Cite This: ACS Omega 2021, 6, 25551-25561

Read Online

\section{ACCESS |}

Wll Metrics \& More

国 Article Recommendations

Supporting Information

ABSTRACT: To increase the stability of cerium scavengers, we doped cerium oxide on mesoporous silica powders for the application of an oxidative stabilizer. The oxidation-reduction reaction involving hydroxyl radicals $\left({ }^{\bullet} \mathrm{OH}\right)$ is investigated with Fenton's test using eight types of $\mathrm{Ce}$ (IV)-mobile compositions of matter 41 (MCM-41) and Ce(III)-MCM-41 powder samples. As confirmed by X-ray photoelectron spectroscopy, the relative amount of $\mathrm{Ce}^{3+}$ inside the mesoporous samples decreases with the increasing time of treatment using the Fenton solution, whereas that of $\mathrm{Ce}^{4+}$ increases. ${ }^{29} \mathrm{Si}$ CP-MAS NMR shows that the condensation of the siloxane bond varies according to the treating time up to $120 \mathrm{~h}$. The mesoporous structure is also analyzed using

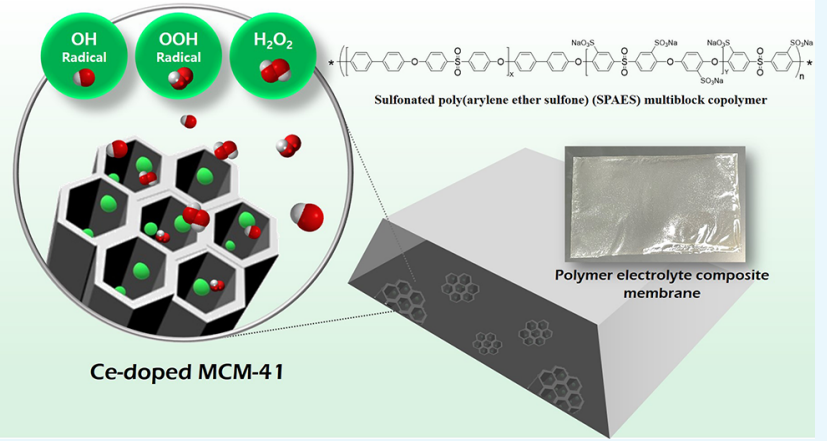
synchrotron small-angle X-ray scattering and nitrogen adsorption.

Further treatment with propane sulfonic acid ensured that the ionic conductivity of the sulfonated mesoporous silica did not decrease. The surface-modified mesoporous silica was incorporated in sulfonated poly(arylene ether sulfone) multiblock membranes. The sulfonated mesoporous silica could overcome the drawbacks of transition metal scavengers, such as a drop in ionic conductivity. Through experiments, we determined that the Ce-doped sulfonated mesoporous silica/sulfonated poly(arylene ether sulfone) composite membranes exhibit high oxidation stability when exposed to hydrogen peroxide and even higher proton conductivity than Nafion at a relative humidity over $60 \%$.

\section{INTRODUCTION}

The fuel cell is one of the most promising clean electrochemical devices that can produce energy without fossil fuel. Proton exchange membrane fuel cells (PEMFCs) have attracted significant attention because they can increase energy efficiency owing to the non-Carnot cycle on power generation instead of the internal combustion engine. As PEMFCs consist of lightweight system components and have high power density, they are considered suitable for automotive and residential applications. ${ }^{1}$

Perfluorosulfonic acid (PFSA) membranes (i.e., Nafion) are most widely used as electrolyte materials for PEMFCs. However, PFSA membranes have several disadvantages such as high cost and insufficient oxidative stability by high gas crossover. ${ }^{2,3}$ Hydrocarbon membranes have attracted attention as alternatives to overcome these disadvantages. Sulfonated aromatic polymers have better thermal stability as well as excellent mechanical strength, as compared with PFSA membranes. In addition, they can be prepared using a lowcost and simple synthetic process. ${ }^{4-10}$
Membrane degradation is another problem for the commercialization of the PEMFC system. Hydroxyl radicals generated during cell operation are one of the main causes of chemical and electrochemical degradation of electrolyte membranes. ${ }^{1-14}$ The generated radicals can lead to degradation of the membranes by attacking the polymer chain, resulting in PEM failure. It is known that reactive chemical species (RCSs) such as hydroxyl and peroxide radicals generated during fuel cell operation can attack the main chain and side chains of the PFSA polymer and cause its decomposition. This decomposition reaction often occurs under low relative humidity $(\mathrm{RH})$ conditions. ${ }^{15-17}$ In addition, Endoh et al. suggested another mechanism, the scission of

Received: July 9, 2021

Published: September 21, 2021 
polymer chains resulting from the decomposition of a sulfonic acid functional group. ${ }^{18}$

Transition metals such as cerium and manganese have been known as radical scavengers to increase the durability of electrolyte membranes by protecting polymers from the attack of hydroxyl radicals. Several investigations have shown promising results with improved durability. However, this approach causes an undesirable side effect of a decrease in the proton conductivity of the membranes. ${ }^{19,20}$ Recently, we have also studied hydrocarbon composite membranes containing cerium ions to evaluate their effect on the oxidative stability. ${ }^{19,21}$ The composite membranes with cerium ions were remarkably stable over $2000 \mathrm{~h}$ in the open circuit voltage (OCV) acceleration evaluation, but they were suspected to diffuse owing to their weak ionic interaction with the matrix sulfonic acid. Organic-type radical scavengers have also been proposed recently and have been reported to improve durability without sacrificing ionic conductivity. ${ }^{22,23}$ However, in this case, the antioxidants are decomposed by themselves, and the performance of the catalyst layer deteriorates because of the outflow of these antioxidants. Thus, it seems that maintaining radical scavenging activity is required for its immobilization to the functional material or the polymer matrix.

In addition to transition metals, cerium oxide (ceria) antioxidation reactions have also been studied for a long time in various scientific fields such as biology, food science, and special redox applications. ${ }^{24-31}$ RCSs are related to multiple cellular injuries, including lipid membrane peroxidation, DNA alteration, damage to proteins, and enzyme inactivation. $^{32-34}$ Ceria has been introduced to bio-applications because of its excellent biocompatibility. ${ }^{24-28}$ Furthermore, it has been used in fuel cells to prevent the polymer degradation in the cells owing to its radical scavenging activity in order to increase the fuel cell durability. ${ }^{35-37}$ These studies have demonstrated the antioxidation effect and radical scavenging activity of ceria. Especially, Xue et al. confirmed the hydroxyl radical scavenging activity of ceria particles using a simple photometric method in vitro. ${ }^{38}$ However, pure ceria has poor thermal stability under a reducing atmosphere and considerable sintering in diverse atmosphere influencing its properties. Moreover, studies on the oxidation stability and evolution of ceria-silica powders in a Fenton test are limited.

Doping cerium on a porous support is a useful method for overcoming ceria instability. It was expected that support materials with high specific surface area, for example, mesoporous silica, could be doped with ceria to improve the thermal stability of ceria and to prevent sintering. Recently, mesoporous silica has attracted much attention and led to critical applications because of the properties of large surface area and easy functionalization. ${ }^{39-43}$ These properties of mesoporous silica can retain a large surface area of ceria at high temperature and under harsh environment. Further, several studies were reported on heteroatom-containing mesoporous materials. ${ }^{44-49}$ To use the abovementioned advantage of mesoporous silica, we prepared mesoporous ceria-silica composites with hexagonal $(p 6 \mathrm{~mm})$ and bicontinuous cubic $(I a 3 d)$ structures using tetraethyl orthosilicate (TEOS) and $\mathrm{Ce}(\mathrm{OH})_{4}$ precursors with a cationic hexadecyltrimethylammonium bromide (CTAB) surfactant under basic conditions. ${ }^{50}$ A cerium ion doped in mesoporous silica acts as a radical scavenger that protects membranes from unstable radicals and hydrogen peroxide through oxidation and reduction reactions, as shown in Figure 1.

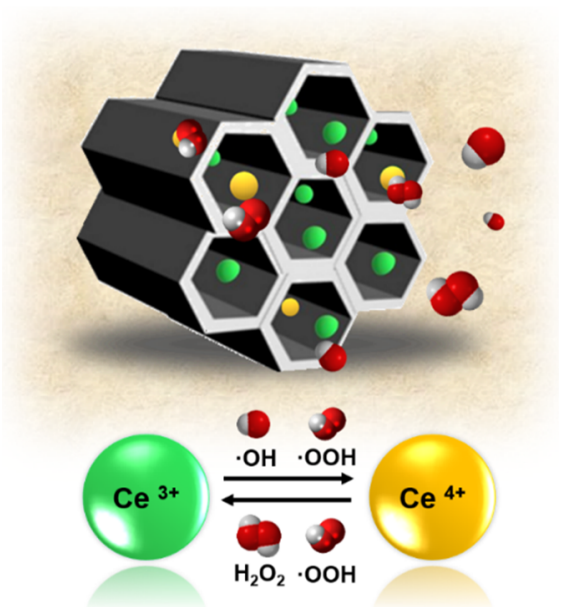

Figure 1. Schematic of radical scavenging mechanism of the Cedoped mesoporous silica.

Here, we report the redox reaction of the prepared mesoporous ceria-silica samples in a Fenton test in detail. A Fenton test of ceria-silica with different cerium contents and mesostructures was performed for $0,12,24,48$, and $120 \mathrm{~h}$ in an aqueous solution containing $4 \mathrm{ppm}$ of $\mathrm{Fe}^{2+}$ and $3 \mathrm{wt} \%$ of $\mathrm{H}_{2} \mathrm{O}_{2}$ at $80^{\circ} \mathrm{C}$. The samples tested by the Fenton reagent were analyzed by small-angle X-ray scattering (SAXS), nitrogen adsorption-desorption, solid-state ${ }^{29} \mathrm{Si}-\mathrm{NMR}, \mathrm{X}$-ray photoelectron spectroscopy (XPS), and inductively coupled plasmaatomic emission spectrometry (ICP-AES). The changes in mesostructure, surface area, chemical bonding, amounts of $\mathrm{Ce}^{3+}$ and $\mathrm{Ce}^{4+}$, internal structure, and cerium contents during the reaction with hydroxyl radicals were investigated through each analysis to study the oxidation stability of ceria-silica. In addition, sulfonated mesoporous ceria-silica particles were incorporated in a homemade multiblock sulfonated poly(arylene ether sulfone) (SPAES) polymer to obtain composite membranes. Treatment with propane sulfonic acid resulted in sulfonated mesoporous ceria-silica, which ensured that the proton conductivity of composite membranes did not decrease. The prepared mesoporous ceria-silica/SPAES composite membranes were tested in an ex situ hydrogen peroxide exposure experiment, which was designed to simulate the atmosphere of actual fuel cell operation. The effect of ceriasilica was analyzed by gel permeation chromatography (GPC) before and after the hydrogen peroxide vapor exposure experiment. Finally, we tested the humidity dependence of the conductivity of the prepared membranes for electrochemical applications.

\section{RESULTS AND DISCUSSIONS}

2.1. Fundamental Physicochemical Characterization of As-Prepared Ce-Doped Mesoporous Silicas. Ce-doped mesoporous silica samples were prepared to investigate the antioxidant role of ceria embedded in the mesoporous silica network. Eight types of samples were prepared by varying four experimental parameters: the $\mathrm{Ce}$ amount (i.e., $\mathrm{Ce} / \mathrm{Si}=0.3$ and $0.5)$, mesostructure of the silica framework (i.e., Ia3d cubic and p6mm hexagonal), oxidation number (electronic state) of Ce atom (i.e., $\mathrm{Ce}^{3+}$ and $\mathrm{Ce}^{4+}$ ), and addition of manganese, as 
Table 1. Characterization of the Ce-Doped Mesoporous Silica Samples Used in This Study ${ }^{a}$

\begin{tabular}{|c|c|c|c|c|c|c|c|c|}
\hline sample & $f_{\mathrm{Ce} / \mathrm{Si}}(\mathrm{mol} \%)$ & $f_{\mathrm{Mn} / \mathrm{Si}}(\mathrm{mol} \%)$ & mesostructure & $S_{\text {BET }}\left(\mathrm{m}^{2} / \mathrm{g}\right)$ & $V_{\mathrm{t}}\left(\mathrm{cm}^{3} / \mathrm{g}\right)$ & $w_{\mathrm{Ce}}(\mathrm{wt} \%)$ & $w_{\mathrm{Mn}}(\mathrm{wt} \%)$ & $f_{\mathrm{Ce}^{3+} / \mathrm{Ce}^{4+}}$ \\
\hline $\operatorname{CCS} 30$ & 30 & 0 & $\operatorname{Ia3d}$ & 494 & 0.43 & 36.0 & 0 & 0.22 \\
\hline CCS30-HR & 30 & 0 & $I a 3 d$ & 419 & 0.27 & 37.8 & 0 & 1.18 \\
\hline HCS30 & 30 & 0 & p6mm & 469 & 0.39 & 32.3 & 0 & 0.24 \\
\hline HCS30-HR & 30 & 0 & p6mm & 348 & 0.24 & 34.0 & 0 & 1.33 \\
\hline HCS50 & 50 & 0 & p6mm & 341 & 0.32 & 41.3 & 0 & 0.22 \\
\hline HCS50-HR & 50 & 0 & p6mm & 231 & 0.25 & 44.2 & 0 & 0.99 \\
\hline CM4 & 30 & 1.5 & p6mm & 412 & 0.37 & 31.6 & 1.5 & 0.23 \\
\hline CM4-HR & 30 & 1.5 & p6mm & 289 & 0.28 & 33.6 & 1.6 & 1.49 \\
\hline
\end{tabular}

${ }^{a}$ Notation: $f_{\mathrm{Ce} / \mathrm{Si}}, f_{\mathrm{Mn} / \mathrm{Si}}=$ molar percentage of $\mathrm{Ce}$ (and $\mathrm{Mn}$ ) precursor to silica precursor in the synthesis gel; mesostructure = cubic and hexagonal mesopore structures of mesoporous materials obtained by SAXS; $S_{\mathrm{BET}}=$ BET specific surface area obtained by the nitrogen adsorption-desorption analysis; $V_{\mathrm{t}}=$ total pore volume obtained at $P / P_{0}=0.99$ of the nitrogen adsorption isotherm; $w_{\mathrm{Ce}}, w_{\mathrm{Mn}}=$ weight percentage of Ce and Mn contents obtained by the ICP-AES analysis; $f_{\mathrm{Ce}^{3+} / \mathrm{Ce}^{4+}}=$ molar ratio of $\mathrm{Ce}^{3+} / \mathrm{Ce}^{4+}$ obtained by the XPS analysis.

Table 2. Ce 3d XPS Analysis before and after the Fenton Test

\begin{tabular}{|c|c|c|c|c|c|c|c|c|c|}
\hline \multirow[b]{2}{*}{ sample } & \multirow[b]{2}{*}{ time treated $(\mathrm{h})$} & \multicolumn{2}{|c|}{ relative peak area (\%) } & \multirow[b]{2}{*}{$\mathrm{Ce}^{3+} / \mathrm{Ce}^{4+}$} & \multirow[b]{2}{*}{ sample } & \multirow[b]{2}{*}{ time treated $(\mathrm{h})$} & \multicolumn{2}{|c|}{ relative peak area (\%) } & \multirow[b]{2}{*}{$\mathrm{Ce}^{3+} / \mathrm{Ce}^{4+}$} \\
\hline & & $\mathrm{Ce}^{3+}$ & $\mathrm{Ce}^{4+}$ & & & & $\mathrm{Ce}^{3+}$ & $\mathrm{Ce}^{4+}$ & \\
\hline \multirow[t]{5}{*}{$\operatorname{CCS} 30$} & 0 & 18.3 & 81.7 & 0.22 & HCS-50 & 0 & 18.1 & 81.9 & 0.22 \\
\hline & 12 & 30.9 & 69.1 & 0.45 & & 12 & 20.1 & 79.9 & 0.25 \\
\hline & 24 & 14.5 & 85.5 & 0.17 & & 24 & 24.3 & 75.7 & 0.32 \\
\hline & 48 & 21.9 & 78.1 & 0.28 & & 48 & 29.0 & 71.0 & 0.41 \\
\hline & 120 & 15.5 & 84.5 & 0.18 & & 120 & 10.5 & 89.5 & 0.12 \\
\hline \multirow[t]{5}{*}{ CCS30-HR } & 0 & 54.2 & 45.8 & 1.18 & HCS50-HR & 0 & 49.8 & 50.2 & 0.99 \\
\hline & 12 & 48.7 & 51.3 & 0.95 & & 12 & 17.8 & 82.2 & 0.22 \\
\hline & 24 & 38.6 & 61.4 & 0.63 & & 24 & 32.0 & 68.0 & 0.47 \\
\hline & 48 & 38.4 & 61.6 & 0.62 & & 48 & 10.4 & 89.6 & 0.12 \\
\hline & 120 & 35.8 & 64.2 & 0.56 & & 120 & 28.8 & 71.2 & 0.40 \\
\hline \multirow[t]{5}{*}{$\operatorname{HCS} 30$} & 0 & 19.4 & 80.6 & 0.24 & CM4 & 0 & 18.7 & 81.3 & 0.23 \\
\hline & 12 & 38.1 & 61.9 & 0.62 & & 12 & 23.3 & 76.7 & 0.30 \\
\hline & 24 & 10.0 & 90.0 & 0.11 & & 24 & 37.9 & 62.1 & 0.61 \\
\hline & 48 & 15.0 & 85.0 & 0.18 & & 48 & 16.7 & 83.3 & 0.20 \\
\hline & 120 & 18.2 & 81.8 & 0.22 & & 120 & 9.6 & 90.4 & 0.11 \\
\hline \multirow[t]{5}{*}{ HCS30-HR } & 0 & 57.0 & 43.0 & 1.33 & CM4-HR & 0 & 59.9 & 40.1 & 1.49 \\
\hline & 12 & 21.2 & 78.8 & 0.27 & & 12 & 55.8 & 44.2 & 1.26 \\
\hline & 24 & 31.4 & 68.6 & 0.46 & & 24 & 47.9 & 52.1 & 0.92 \\
\hline & 48 & 21.2 & 78.8 & 0.27 & & 48 & 43.8 & 56.2 & 0.78 \\
\hline & 120 & 28.3 & 71.7 & 0.40 & & 120 & 22.9 & 77.1 & 0.30 \\
\hline
\end{tabular}

listed in Table 1. Nitrogen adsorption-desorption isotherms were used to characterize the Brunauer-Emmett-Teller (BET) surface area and the total pore volume before and after the Fenton test. Ordered Ce-doped mesoporous samples showed high surface areas and pore volumes in the ranges of $231-494 \mathrm{~m}^{2} / \mathrm{g}$ and $0.24-0.43 \mathrm{~cm}^{3} / \mathrm{g}$, respectively. The weight percentages of $\mathrm{Ce}$ and $\mathrm{Mn}$ and the molar ratio of $\mathrm{Ce}^{3+} / \mathrm{Ce}^{4+}$ for the as-prepared samples were obtained by ICP-AES and XPS analyses, respectively. The results are listed in Table 1.

2.2. Weight and ICP Analysis after the Fenton Test. The Fenton test was employed to analyze the anti-oxidative performance of Ce-doped mesoporous silica samples. The total weights of each sample were measured after the Fenton test at $80{ }^{\circ} \mathrm{C}$ for $120 \mathrm{~h}$. Generally, $\mathrm{Fe}^{2+}$ is oxidized by hydrogen peroxide to $\mathrm{Fe}^{3+}$, forming a hydroxyl radical and a hydroxide ion (eq 2). $\mathrm{Fe}^{3+}$ is then reduced back to $\mathrm{Fe}^{2+}$ by another molecule of hydrogen peroxide, forming a hydroperoxyl radical and a proton (eq 3). The net effect is a disproportionation of hydrogen peroxide to generate two free radical species with water $\left(\mathrm{H}^{+}+\mathrm{OH}^{-}\right)$as a byproduct.

$$
\mathrm{Fe}^{2+}+\mathrm{H}_{2} \mathrm{O}_{2} \rightarrow \mathrm{Fe}^{3+}+\mathrm{HO}^{\bullet}+\mathrm{OH}^{-}
$$

$$
\mathrm{Fe}^{3+}+\mathrm{H}_{2} \mathrm{O}_{2} \rightarrow \mathrm{Fe}^{2+}+\mathrm{HOO}^{\bullet}+\mathrm{H}^{+}
$$

The powerful, nonselective oxidant hydroxyl and hydroperoxyl free radicals generated by this process then engage in secondary reactions to decompose any chemical bonds. However, the Ce-doped mesoporous silica samples prepared in this study remained over $50 \mathrm{wt} \%$ after the Fenton test for $120 \mathrm{~h}$, as listed in Table 2. Each sample's remaining weight was in the range of $45-85$ wt \% based on the untreated weights. The HCS30 (i.e., hexagonal mesoporous ceria-silica with Ce/ $\mathrm{Si}=0.3)$ sample showed the best performance up to $85 \mathrm{wt} \%$ in weight retention. Both $\mathrm{Ce}$ and $\mathrm{Mn}$ contents increased slightly, which suggests that the silica $(-\mathrm{O}-\mathrm{Si}-\mathrm{O}-)$ bonds are slightly more decomposed than other $-\mathrm{O}-\mathrm{Ce}-\mathrm{O}-$ and $-\mathrm{O}-$ $\mathrm{Mn}-\mathrm{O}-$ bonds. The overall results of the weight and ICP analyses after the Fenton test are summarized in Table S1.

2.3. XPS Analysis. The electronic state of cerium present in the siliceous mesostructures was observed by analyzing XPS spectra of the Ce-doped mesoporous silica samples before and after the Fenton test. Figures S1-S8 show the Ce 3d core-level XPS spectra of the CCS30, CCS30-HR, HCS30, HCS30-HR, HCS50, HCS50-HR, CM4, and CM4-HR samples before and after the Fenton test for $120 \mathrm{~h}$, respectively. The binding 

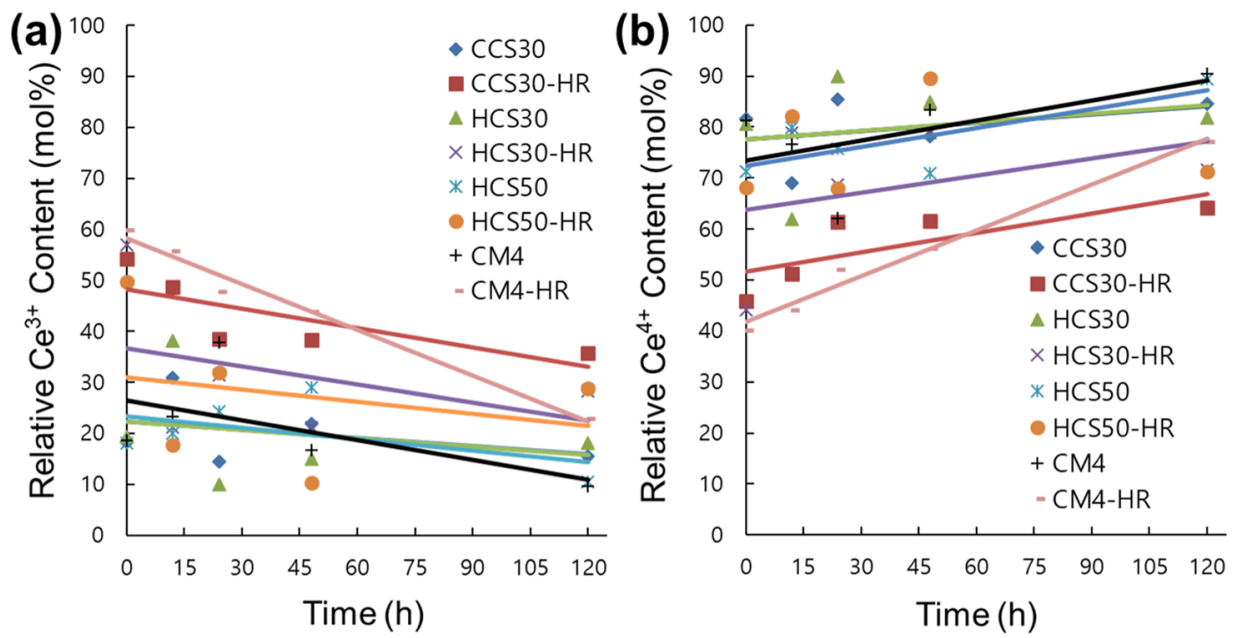

Figure 2. Variation in the cerium electronic state obtained from the XPS analysis according to the treatment time in the Fenton solution: (a) Ce ${ }^{3+}$ and (b) $\mathrm{Ce}^{4+}$ contents.
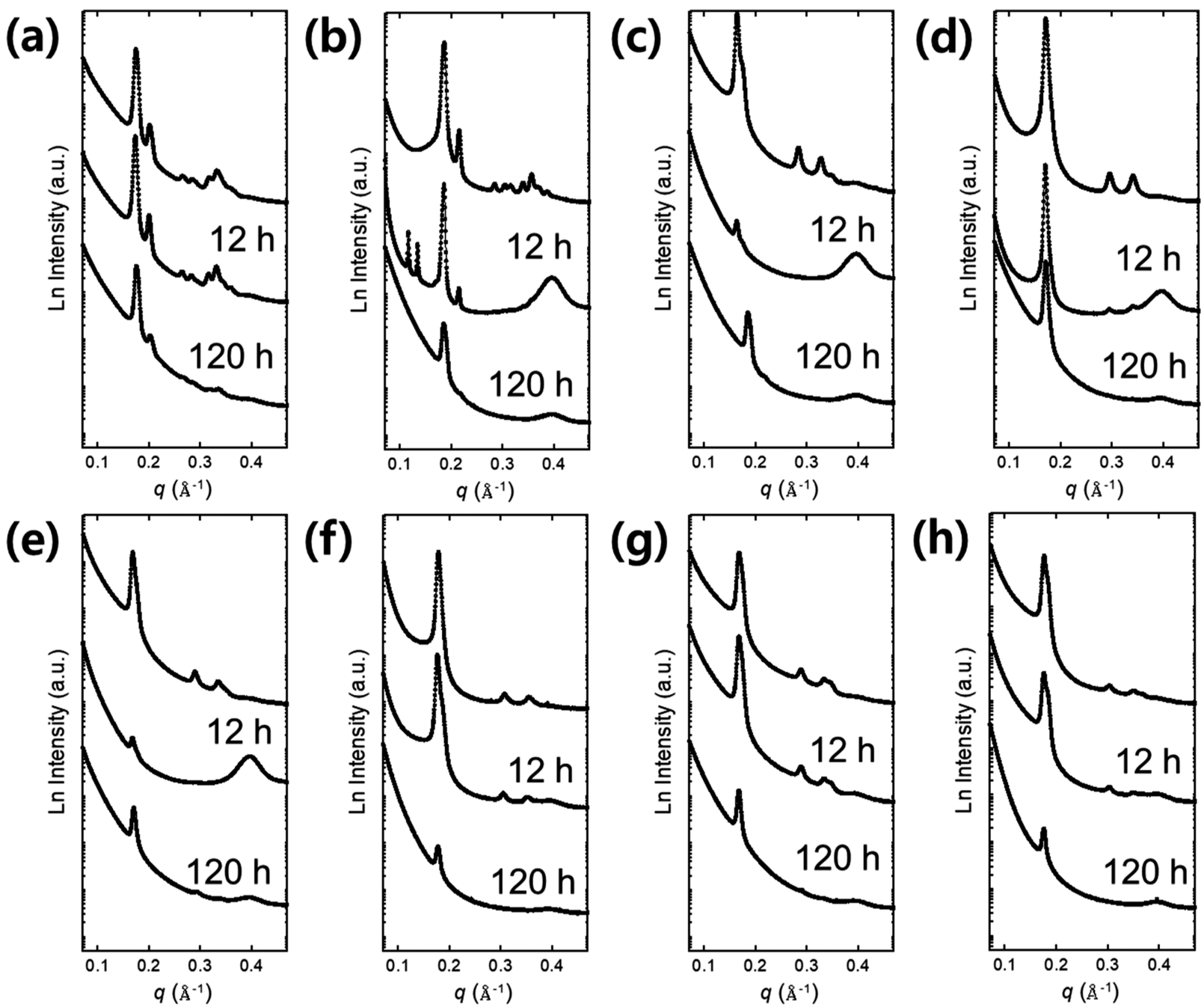

Figure 3. Variation in the SAXS patterns before and after the Fenton test for 12 and $120 \mathrm{~h}$ using the following samples: (a) CCS30, (b) CCS30HR, (c) HCS30, (d) HCS30-HR, (e) HCS50, (f) HCS50-HR, (g) CM4, and (h) CM4-HR.

energies at 883 and $890 \mathrm{eV}$ are associated with the Ce $3 \mathrm{~d}_{5 / 2}$ state, whereas the peak at $900 \mathrm{eV}$ is due to the spin-orbit coupling of the Ce $3 \mathrm{~d}_{5 / 2}$ and Ce $3 \mathrm{~d}_{3 / 2}$ states. $^{50,51}$ The other three peaks at 902,908 , and $918 \mathrm{eV}$ refer to the Ce $3 d_{3 / 2}$ state.
All six peaks are the characteristic peaks for the binding energies related to the $\mathrm{Ce}^{4+}$ state linked to $\mathrm{CeO}_{2}{ }^{50,51}$ However, it is well-known that two peaks at 886 and $905 \mathrm{eV}$ confirm the presence of the Ce $3 d_{5 / 2}$ and $\mathrm{Ce} 3 d_{3 / 2}$ states of 
Table 3. Physicochemical Analysis of Nitrogen Sorption before and after the Fenton Test ${ }^{a}$

\begin{tabular}{|c|c|c|c|c|c|c|c|c|c|}
\hline sample & time treated $(\mathrm{h})$ & $S_{\mathrm{BET}}\left(\mathrm{m}^{2} / \mathrm{g}\right)$ & $V_{\mathrm{t}}\left(\mathrm{cm}^{3} / \mathrm{g}\right)$ & $D_{\mathrm{KJS}}(\mathrm{nm})$ & sample & time treated $(\mathrm{h})$ & $S_{\mathrm{BET}}\left(\mathrm{m}^{2} / \mathrm{g}\right)$ & $V_{\mathrm{t}}\left(\mathrm{cm}^{3} / \mathrm{g}\right)$ & $D_{\mathrm{KJS}}(\mathrm{nm})$ \\
\hline \multirow[t]{3}{*}{$\operatorname{CCS} 30$} & 0 & 494 & 0.48 & 3.3 & HCS50 & 0 & 341 & 0.36 & 3.5 \\
\hline & 12 & 475 & 0.55 & 3.3 & & 12 & 289 & 0.35 & 3.3 \\
\hline & 120 & 384 & 0.53 & 3.1 & & 120 & 238 & 0.37 & 3.3 \\
\hline \multirow[t]{3}{*}{ CCS30-HR } & 0 & 419 & 0.36 & 3.0 & HCS50-HR & 0 & 231 & 0.30 & 3.0 \\
\hline & 12 & 363 & 0.33 & 2.9 & & 12 & 222 & 0.22 & 3.1 \\
\hline & 120 & 267 & 0.45 & 5.8 & & 120 & 118 & 0.29 & 9.5 \\
\hline \multirow[t]{3}{*}{$\operatorname{HCS} 30$} & 0 & 449 & 0.45 & 3.5 & CM4 & 0 & 412 & 0.42 & 3.4 \\
\hline & 12 & 349 & 0.38 & 3.4 & & 12 & 362 & 0.42 & 3.4 \\
\hline & 120 & 361 & 0.47 & 3.2 & & 120 & 285 & 0.51 & 7.3 \\
\hline \multirow[t]{3}{*}{ HCS30-HR } & 0 & 348 & 0.32 & 3.0 & CM4-HR & 0 & 289 & 0.33 & 3.1 \\
\hline & 12 & 265 & 0.28 & $3.0,7.7$ & & 12 & 204 & 0.31 & 3.1 \\
\hline & 120 & 265 & 0.40 & $2.7,5.8$ & & 120 & 151 & 0.41 & 8.6 \\
\hline
\end{tabular}

${ }^{a}$ Notation: $S_{\mathrm{BET}}=\mathrm{BET}$ specific surface area obtained by the nitrogen adsorption-desorption analysis; $V_{\mathrm{t}}=$ total pore volume obtained at $P / P_{0}=$ 0.99 of the nitrogen adsorption isotherm; $D_{\mathrm{KJS}}=$ mesopore diameter at the maximum of the PSD curve determined by the KJS method.

$\mathrm{Ce}^{3+}$, respectively, arising from $\mathrm{Ce}_{2} \mathrm{O}_{3}$ species obtained by reduction of $\mathrm{CeO}_{2} \cdot{ }^{50,51}$ The $\mathrm{Ce} 3 \mathrm{~d}$ spectra of the untreated CCS30 (Figure S1), HCS30 (Figure S3), HCS50 (Figure S5), and CM4 (Figure S7) samples exhibit more than six peaks in the range of $880-920 \mathrm{eV}$, representing the electronic state of mainly $\mathrm{Ce}^{4+}$. In contrast, the $\mathrm{Ce}^{3+}$ state is more abundant than the $\mathrm{Ce}^{4+}$ state inside reduced but untreated CCS30-HR (Figure S2), HCS30-HR (Figure S4), HCS50-HR (Figure S6), and CM4-HR (Figure S8) samples. However, it was found that all the samples treated by Fenton's reagents for $120 \mathrm{~h}$ contained an increased amount of the $\mathrm{Ce}^{4+}$ state, as shown in Figures $\mathrm{S} 1-\mathrm{S} 8$.

To quantify the relative amounts of $\mathrm{Ce}^{3+}$ and $\mathrm{Ce}^{4+}$, each spectrum of Ce $3 \mathrm{~d}$ in Figures $\mathrm{S} 1-\mathrm{S} 8$ was deconvoluted into 5-8 separate peaks using the Gaussian fitting method. From the integration of the deconvoluted peaks, ${ }^{47}$ the relative peak area (i.e., $\mathrm{Ce}^{3+}$ and $\mathrm{Ce}^{4+}$ ) and the ratio of $\mathrm{Ce}^{3+} / \mathrm{Ce}^{4+}$ were obtained according to the time treated by Fenton's reagents listed in Table 2. The overall trend for the $\mathrm{Ce}^{3+}$ and $\mathrm{Ce}^{4+}$ contents is also depicted as a function of the treatment time by Fenton's reagents in Figure 2. As shown in Figure 2a,b, the relative $\mathrm{Ce}^{3+}$ content decreased gradually with a slight fluctuation for all samples, and the $\mathrm{Ce}^{4+}$ content increased gradually with a fluctuation. The molar ratio of $\mathrm{Ce}^{3+} / \mathrm{Ce}^{4+}$ decreased for all samples showing a significant fluctuation, as demonstrated in Table 2. XPS analysis represents the wellknown reaction of Fenton's reagents, including $\mathrm{Fe}^{2+} / \mathrm{Fe}^{3+}$ pairs with hydrogen peroxide replaced partially by the oxidationreduction reaction between $\mathrm{Ce}^{3+}$ and $\mathrm{Ce}^{4+}$. Moreover, this suggests that bond cleavage can be hindered by this additional oxidation-reduction reaction between $\mathrm{Ce}^{3+}$ and $\mathrm{Ce}^{4+}$ with free radicals.

2.4. SAXS and $\mathbf{N}_{2}$ Sorption Analysis. Synchrotron SAXS patterns were analyzed to investigate the structural stability of the Ce-doped mesoporous silica samples before and after the Fenton test. The results are shown in Figure 3. The highly ordered cubic $(I a 3 d)$ mesostructures of the CCS30 and CCS30-HR samples are demonstrated in Figure 3a,b, and the hexagonal $(p 6 \mathrm{~mm})$ structures of other samples are shown in Figure $3 \mathrm{c}-\mathrm{h}$. The untreated samples exhibited well-defined mesostructures with strong high-order peaks as well as an intense Bragg peak in the range of $q=0.18-0.20 \AA^{-1}$. However, the samples treated by Fenton's reagents up to 12 and $120 \mathrm{~h}$ exhibited reduced structural integrity, as shown in Figure 3. Note that the 3D cubic mesostructured CCS30 sample exhibits higher structural stability at a treatment time of $12 \mathrm{~h}$, as shown in Figure 3a. In addition, in the case of the cubic structure including reduced ceria (Figure $3 b$ ), the SAXS diffraction pattern showed the formation of large pores or a new structure when treated for $12 \mathrm{~h}$. All the samples treated up to $120 \mathrm{~h}$ showed only a single Bragg. In contrast, the pristine MCM-41 sample without Ce showed better structural stability after the Fenton test, the data of which are not shown here. Therefore, the order to disorder transition of the mesophase of the SAXS pattern related to the Fenton test is attributed to the oxidation-reduction reaction of cerium oxides chemically linked with silica inside the mesoporous framework wall.

To evaluate the variation in the mesoporous structure after the Fenton test, the BET specific surface area, pore volume, and pore size distribution (PSD) of the samples were analyzed using nitrogen adsorption-desorption isotherms. In Figure S9, the $\mathrm{N}_{2}$ sorption isotherms of the Ce-doped samples are shown before and after the Fenton test for 12 and $120 \mathrm{~h}$. The PSD curves are shown in Figure S10. The related physicochemical parameters obtained from these isotherms are listed in Table 3. The nitrogen isotherms of the initial and $12 \mathrm{~h}$ treated samples are type I + IV mixed isotherms with capillary condensation steps at $P / P_{0}$ of about $0.2-0.3$ with negligible hysteresis.

In contrast, the 120 h-treated samples exhibit high gas uptake and type $\mathrm{A}$ hysteresis at $P / P_{0}$ above 0.5 , representing any change in the pore size depending on the nanostructure, as shown in Figure S9. Type A hysteresis indicates that the cylindrical pore shapes are maintained but increased in size. The specific BET surface area is in the range of $118-494 \mathrm{~m}^{2} / \mathrm{g}$, and the total pore volumes $\left(V_{\mathrm{t}}\right)$ vary from 0.22 to $0.55 \mathrm{~cm}^{2} / \mathrm{g}$. As for the surface area variation, the $120 \mathrm{~h}$-treated samples display the lowest values for all samples. As can be calculated using the information listed in Table 3, the surface area of the $120 \mathrm{~h}$ treated samples was reduced by $20-49 \%$ depending on the sample, as compared with the initial sample. The reduced $\mathrm{Ce}^{3+}$-rich samples showed a more significant reduction in the surface area, as compared with the $\mathrm{Ce}^{4+}$-rich samples. In particular, the maximum decrease in the surface areas of the HCS50-HR and CM4-HR samples were up to 51 and 52\%, respectively. According to the PSD curves in Figure S10, the adsorbed pore volumes did not change significantly until the $12 \mathrm{~h}$ treatment. However, the $120 \mathrm{~h}$-treated samples showed a significant decrease in adsorbed amount. In addition, the pore size did not vary considerably in the range of 3.0-3.5 nm until the $12 \mathrm{~h}$ treatment was completed. However, after $120 \mathrm{~h}$ 
treatment, all the reduced $\mathrm{Ce}^{3+}$-rich CCS30-HR, HCS30-HR, and HCS50-HR samples as well as the CM4 and CM4-HR samples containing manganese showed enlarged and bimodal pore peaks in the range of 5.8-9.5 $\mathrm{nm}$. These results strongly indicate that the $\mathrm{Ce}^{3+}$-rich samples reacted more to hydroxyl radicals generated by the Fenton reagent, resulting in more changes in the mesoporous structure. In particular, the $\mathrm{Ce}^{3+}$ ions and $\mathrm{Ce} / \mathrm{Mn}$ co-ions that are chemically bonded to the silica, forming the mesoporous framework, reacted more with radicals and were oxidized; they separated from the surrounding silica bonds and caused the pore sizes to increase.

2.5Preparation of the Composite Membranes and Hydrogen Peroxide Vapor Exposure Test. As shown in Figure 4A, an electrolyte ceria-silica composite membrane

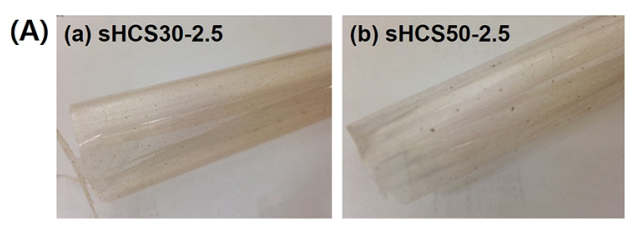

(B)
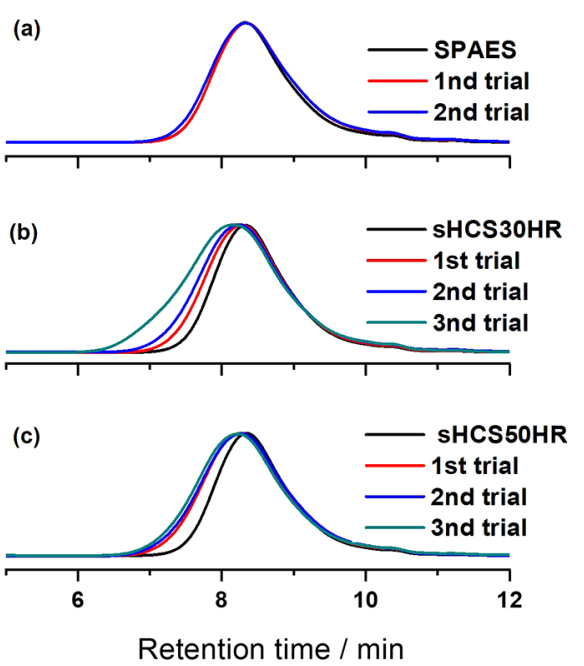

Figure 4. (A) Mesoporous ceria-silica-incorporated SPAES composite membranes containing sHCS30-HR of 2.5 wt \% (a) and sHCS50$\mathrm{HR}$ of $2.5 \mathrm{wt} \%$ (b) for the $\mathrm{H}_{2} \mathrm{O}_{2}$ exposure experiment. (B) GPC data for the $\mathrm{H}_{2} \mathrm{O}_{2}$ exposure test of (a) SPAES multiblock copolymer, (b) sHCS30-HR/SPAES, and (c) sHCS50-HR/SPAES composite membrane samples. Experimental conditions are under $10 \%$ of $\mathrm{H}_{2} \mathrm{O}_{2}$ and water vapor at $120^{\circ} \mathrm{C}$ for $36 \mathrm{~h}$.

containing 2.5 wt \% sHCS30-HR and sHCS50-HR was prepared. This concentration was optimum in a previous report. ${ }^{19,22}$ The oxidative stability of the composite membranes was investigated through a hydrogen peroxide vapor exposure test that can simulate OCV operation of the fuel cell. The composite electrolyte membrane was exposed to hydrogen peroxide under $120{ }^{\circ} \mathrm{C}$ and $10 \% \mathrm{RH}$ for $36 \mathrm{~h}$. The prepared electrolyte membrane was randomly cut into $4 \mathrm{~cm}^{2}$ with $2-3$ samples. After all samples were placed in the chamber, the exposure test for all samples was conducted under exactly the same condition.

The molecular weight changes of the polymer before and after the experiment were measured by GPC. The results are shown in Figure $4 \mathrm{~B}$ and Table 4. The thickness of all membranes before and after the experiment was almost unchanged, and the pristine SPAES polymer was reduced by
Table 4. $\mathrm{H}_{2} \mathrm{O}_{2}$ Exposure Test for Copolymer/Mesoporous Material Composite membranes ${ }^{a}$

\begin{tabular}{|c|c|c|c|c|c|c|}
\hline sample and trial & $\begin{array}{l}R_{\mathrm{t}, \max } \\
(\mathrm{min})\end{array}$ & $\begin{array}{c}M_{\mathrm{n}} \\
(\mathrm{kDa})\end{array}$ & $\begin{array}{c}M_{\mathrm{w}} \\
(\mathrm{kDa})\end{array}$ & PDI & $\begin{array}{l}V_{\mathrm{M}} \\
(\%)\end{array}$ & $t(\mu \mathrm{m})$ \\
\hline SPAES & 8.33 & 96 & 237 & 2.48 & $\mathrm{~N} / \mathrm{A}$ & \\
\hline SPAES_tr1 & 8.33 & 85 & 228 & 2.67 & -11.5 & 73 \\
\hline SPAES_tr2 & 8.33 & 87 & 243 & 2.81 & -9.4 & 76 \\
\hline sHCS30HR & 8.33 & 103 & 237 & 2.30 & N/A & \\
\hline sHCS30HR_tr1 & 8.28 & 106 & 278 & 2.61 & $\sim 0$ & 71 \\
\hline sHCS30HR_tr2 & 8.23 & 108 & 314 & 2.91 & $\sim 0$ & 73 \\
\hline sHCS30HR_tr3 & 8.17 & 119 & 454 & 3.81 & $\sim 0$ & 105 \\
\hline sHCS50HR & 8.35 & 102 & 231 & 2.27 & $\mathrm{~N} / \mathrm{A}$ & \\
\hline sHCS50HR_tr1 & 8.27 & 106 & 294 & 2.77 & $\sim 0$ & 73 \\
\hline sHCS50HR_tr2 & 8.27 & 103 & 307 & 2.99 & $\sim 0$ & 73 \\
\hline sHCS50HR_tr3 & 8.22 & 111 & 334 & 3.02 & $\sim 0$ & 108 \\
\hline
\end{tabular}

${ }^{a}$ Experimental condition for $\mathrm{H}_{2} \mathrm{O}_{2}$ exposure: $10 \% \mathrm{H}_{2} \mathrm{O}_{2}$ and water vapor at $120{ }^{\circ} \mathrm{C}$ for $36 \mathrm{~h} ; R_{\mathrm{t}, \max }=$ retention time at maximum taken from the GPC analysis; $M_{\mathrm{n}}=$ number average molecular weight; $M_{\mathrm{w}}=$ weight average molecular weight; PDI $=$ polydispersity index $\left(=M_{\mathrm{w}} /\right.$ $\left.M_{\mathrm{n}}\right) ; V_{\mathrm{M}}=$ variation of the molecular weight (degradation ratio) calculated using the number average molecular weight before and after the test $\left(=100 \times\left(M_{\mathrm{n}, \text { test }}-M_{\mathrm{n}, 0}\right) / M_{\mathrm{n}, 0}\right) ; t=$ membrane thickness.

about $10 \%$ on the average of the number average molecular weight after the experiment. Especially, the profile of GPC for the low-molecular-weight polymer increased. This is presumed to be the decomposition of the polymer by hydrogen peroxide. As a result, the molecular weight was reduced. At the same time, the PDI of the polymer was widened (Figure 4B(a))

On the contrary, the molecular weight of the composite membrane containing mesoporous silica did not decrease after evaluating the oxidation stability (Figure 4B (b,c)). This is consistent with the results of the Fenton experiment of mesoporous ceria-silica, which confirms that ceria-silica inhibits radical oxidation decomposition. These results are similar to those of previous studies in that the oxidation stability is improved by adding pure cerium metal to the membrane. ${ }^{19,52}$ Specifically, the molecular weight corresponding to the low retention time was partially increased after the hydrogen peroxide exposure experiment in the case of composite membranes (Figure $4 \mathrm{~B}(\mathrm{~b}, \mathrm{c})$ ). This phenomenon occurred in all samples, although the increase was slightly different depending on the sample batch. This suggests that intermolecular recombination occurs in the SPAES molecule, as already was reported, which further improves the electrolyte membrane's durability. ${ }^{22,53}$ Our previous study suggested that the generated radicals could recombine with the polymer and change its conformation and molecular weight. Specifically, if the radicals attack the polymer chains during the peroxide exposure test, reactive radicals could be transferred to the polymer chain and eventually lead to an intermolecular recombination reaction with radicals on other polymers. We reported that multiangle light scattering revealed an increase in the $Z$-average diameter of the polymer after the oxidative stability test. ${ }^{22}$

2.6. Proton Conductivity of the Composite Membranes. The humidity-dependent proton conductivity of the SPAES and sHCS-50HR composite membranes was obtained in the $\mathrm{RH}$ range from 20 to $90 \%$ at $80^{\circ} \mathrm{C}$, as shown in Figure 5. The composite membranes containing mesoporous silica particles exhibited better ionic conductivity at an $\mathrm{RH}$ of $60 \%$ or higher than commercial perfluorinated Nafion. It showed 


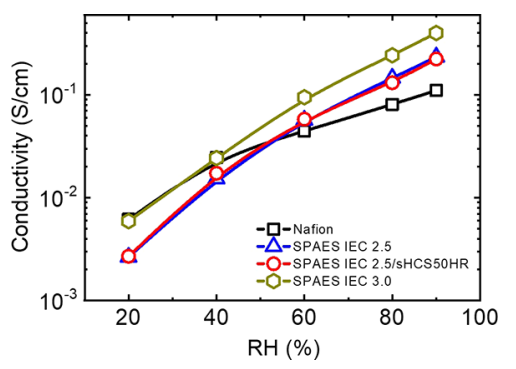

Figure 5. Humidity dependence of the proton conductivity for Nafion, SPAES (IEC 3.0 and 2.5), and mesoporous ceria-silica/ SPAES (IEC 2.5) composite membranes at $80{ }^{\circ} \mathrm{C}$.

somewhat lower ionic conductivity than the pristine multiblock polymer; however, the conductivity of the composite membrane was similar to that of the pristine polymers considering different ion-exchange capacities (IECs). Mesoporous ceria-silica has excellent chemical resistance, but it does not affect the ion conductivity of the composite membranes. The structure of embedded ceria on mesoporous silica might explain this positive effect. The embedded ceria molecules do not contact directly with sulfonic acid of the SPES. Thus, the proton conductivity was maintained even after the addition of sHCS-50HR to the multiblock polymer. Furthermore, it is considered that it does not affect the formation of ion transport channels by interfering with the phase separation of the hydrophilic/hydrophobic block, which is the most important reason for the high conductivity of the block copolymers. This is the advantage of mesoporous ceriasilica, which seems contrary to contemporary antioxidants such as cerium and manganese. The pure cerium and manganese structure appear to interact between the additives, and the polymer electrolyte interferes with the ion transport pathway. ${ }^{19,54}$ However, a mesoporous ceria-silica antioxidant does not disturb ionic conductivity when the oxidation stability is maintained.

\section{CONCLUSIONS}

We synthesized mesoporous silica as additives to increase the durability of the proton exchange membranes. Feasibility as an oxidative stabilizer was confirmed not only by itself but with respect to the additives in the multiblock SPAES. During the hydrogen peroxide exposure of the Ce-doped mesoporous silica samples using Fenton's reagents, $\mathrm{Ce}^{3+}$ changed to $\mathrm{Ce}^{4+}$ more actively, and the $\mathrm{Ce}^{4+}$ content remained constant or increased. The specific BET surface areas decreased upon exposure to hydrogen peroxide, and the PSD broadened further with the increase in the amount of $\mathrm{Ce}^{3+}$ in the doped mesoporous sample. This result clearly shows that $\mathrm{Ce}^{3+}$ linked with silica is a more active hydrogen peroxide than $\mathrm{Ce}^{4+}$. The Ce-doped mesoporous silica also scavenges radicals as additives of the multiblock SPES membranes. The sHCS50HR composite membranes did not degrade under peroxide exposure, whereas pristine multiblock membranes experienced a deterioration in their molecular weight. Moreover, sHCS$50 \mathrm{HR}$ could maintain the inherent ion conductivity of the pristine membrane and exceed that of the Nafion. The Cedoped mesoporous silica with sulfonic acid seems a very promising oxidative additive to increase the durability of the proton exchange membrane while maintaining ionic conductivity.

\section{EXPERIMENTAL SECTION}

4.1. Materials. To prepare mesoporous ceria-silica, CTAB (98\%, Aldrich) was used as a template, and TEOS (98\%, Aldrich), cerium(IV) hydroxide $\left(\mathrm{Ce}(\mathrm{OH})_{4}\right.$, Aldrich), and manganese(II) acetate tetrahydrate $\left(\mathrm{Mn}(\mathrm{OAc})_{2} \cdot 4 \mathrm{H}_{2} \mathrm{O}, \mathrm{Al}-\right.$ drich) were used as inorganic precursors. Ammonium hydroxide $\left(28-30 \% \mathrm{NH}_{3}\right.$ in water, Aldrich) was used as a base catalyst, and ethanol (EtOH, Aldrich) was used as a solvent. Deionized water was prepared in the laboratory. A hydrogen peroxide solution (3 wt \% in water, Aldrich) and iron(II) sulfate heptahydrate $\left(\mathrm{FeSO}_{4} \cdot 7 \mathrm{H}_{2} \mathrm{O}\right.$, Aldrich) were used as Fenton reagents. All the chemicals were used as received without further purification. To synthesize sulfonated multiblock poly(arylene ether sulfone) copolymer, 4,4' dihydroxy biphenyl, 4,4'-difluorodiphenyl sulfone (FDPS), and 3,3'-disulfonated-4,4'-difluorodiphenyl sulfone (DSFDPS) were obtained from Yanjin (China). FDPS and DSFDPS were used after the recrystallizing process. Potassium hydroquinone sulfonate (HQS) was obtained from TCI. Potassium carbonate $\left(\mathrm{K}_{2} \mathrm{CO}_{3}\right.$, Aldrich), N,N-dimethylacetamide (DMAc, anhydrous $\geq 99.9 \%$, Aldrich), and dimethylsulfoxide (DMSO, anhydrous $\geq 99.9 \%$, Aldrich) were used after drying over molecular sieves (3 Å). A 3-(trihydroxysilyl)-1-propane sulfonic acid solution (30-35\% in water) (THSPSA, Gelest) was used to modify the sulfonic acid group on the surface of mesoporous materials.

4.2. Preparation of Ce-Doped and Mn-Ce-Doped Mesoporous Silica Samples. Ce- and Mn-doped mesoporous ceria-silica samples were prepared using the procedure described in our previous reports. ${ }^{50,51,55}$ Hexagonally $(p 6 \mathrm{~mm})$ and cubic $(\mathrm{Ia} 3 \mathrm{~d})$ ordered mesoporous composites with $\mathrm{Ce} / \mathrm{Si}$ $=0.3$ and 0.5 were prepared in the presence of CTAB surfactant under ammonia basic conditions. In a typical synthesis of HCS50 (i.e., hexagonal mesoporous ceria-silica with $\mathrm{Ce} / \mathrm{Si}=0.5$, Table 1 ), $3.0 \mathrm{~g}$ of $\mathrm{CTAB}$ was dissolved in a mixture of $60 \mathrm{~mL}$ of deionized water, $91.2 \mathrm{~mL}$ of ethanol, and $70 \mathrm{~mL}$ of a $\mathrm{NH}_{4} \mathrm{OH}$ solution under vigorous stirring for $1 \mathrm{~h}$ at ambient conditions in a glass bottle. Next, $6.0 \mathrm{~mL}$ of TEOS was added to the solution, followed by adding $2.80 \mathrm{~g}$ of cerium hydroxide $\left(\mathrm{Ce}(\mathrm{OH})_{4}\right)$ after $30 \mathrm{~min}$. The precipitates were obtained by stirring for further $20 \mathrm{~h}$ at $25^{\circ} \mathrm{C}$, followed by aging at $100{ }^{\circ} \mathrm{C}$ for $24 \mathrm{~h}$ in a convection oven. The final samples were obtained after filtering with an adequate amount of deionized water as well as ethanol repeatedly. The surfactant was removed completely from the as-synthesized sample by calcination at $550{ }^{\circ} \mathrm{C}$ for $5 \mathrm{~h}$ under flowing air.

Mesoporous ceria(III)-silica composite samples were prepared by reduction of ceria(IV)-silica samples under the flow of an $\mathrm{H}_{2} / \mathrm{N}_{2}$ gas mixture $\left(7 \mathrm{vol} \%\right.$ of $\mathrm{H}_{2}$ ) at $850{ }^{\circ} \mathrm{C}$ for $5 \mathrm{~h}$ in a tube furnace, as described in previous reports. ${ }^{50,51,55}$ Nomenclature and physicochemical properties of eight types of mesoporous samples are listed in Table 1.

4.3. Fenton's Test of Mesoporous Powder Samples. Each $50 \mathrm{mg}$ of Ce-doped mesoporous silica and Mn-doped mesoporous ceria-silica powder samples was immersed in $10 \mathrm{~g}$ of Fenton reagents containing $4 \mathrm{ppm}$ of $\mathrm{Fe}^{2+}$ and $3 \mathrm{wt} \%$ of $\mathrm{H}_{2} \mathrm{O}_{2}$ in deionized water, respectively. Subsequently, the sample mixtures were placed in a convection oven at $80{ }^{\circ} \mathrm{C}$ for 12, 24, 48, and $120 \mathrm{~h}$. Each sample weight was obtained after filtration and drying of the remaining solid powder.

4.4. Characterization of Mesoporous Samples before and after Fenton's Test. The weight percentages of Ce and $\mathrm{Mn}$ in the samples were obtained using JobinYvon Ultima 2C, 
(a)

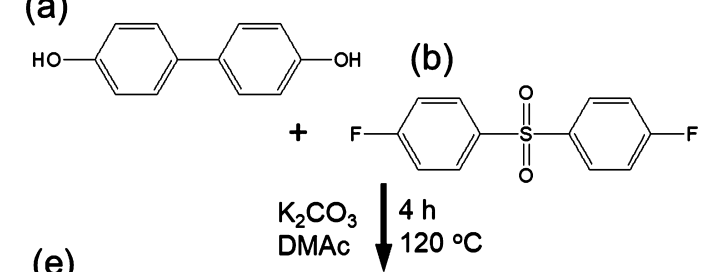

(c)

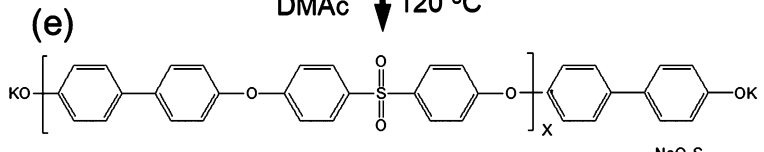

Hydrophobic oligomer

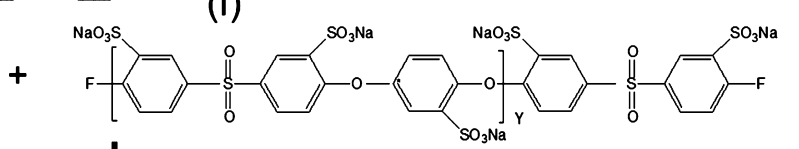

(g)

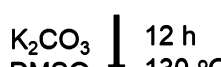

$\mathrm{DMAC}+\mathrm{DMSO} \vee 130^{\circ} \mathrm{C}$

Sulfonated hydrophilic oligomer

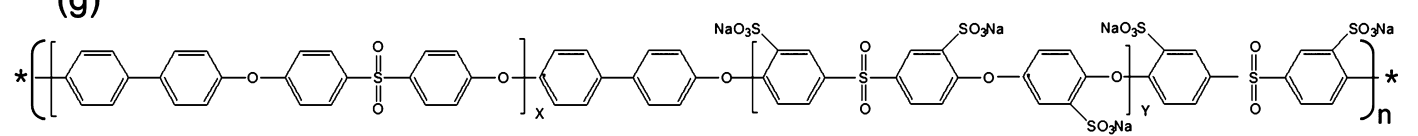

Sulfonated poly(arylene ether sulfone) (SPAES) multiblock copolymer

Figure 6. Schematic of the chemical structures and reactions for monomer, oligomer, and multiblock copolymer. (a) 4,4-dihydroxybiphenyl, (b) 4fluorophenyl sulfone (FPS), (c) 3,3'-disulfonated-4,4'-difluorophenyl sulfone (DSDFPS), (d) potassium HQS, (e) hydroxy-terminated hydrophobic oligomer precursor, (f) fluorine-terminated hydrophilic oligomer precursor, and (g) multiblock poly(arylene ether sulfone).

an inductively coupled plasma optical emission spectrometer (ICP-AES, $\lambda=395.254 \mathrm{~nm}$ ) at the Korea Basic Science Institute (KBSI) Seoul center. As for the final data, the average value was obtained from three trials. The electronic state of ceria was obtained from XPS measurements using a Theta Probe AR-XPS System (Thermo Fischer Scientific, UK) with monochromatic $\mathrm{Al} \mathrm{K} \alpha(h \nu=1486.6 \mathrm{eV}) \mathrm{X}$-ray radiation at 15 $\mathrm{kV}$ and $150 \mathrm{~W}$ at KBSI Busan center. The data were corrected by setting the binding energy of the adventitious carbon ( $\mathrm{C}$ 1s) to $284.6 \mathrm{eV}$. The analysis was performed under a pressure of lower than $7.5 \times 10^{-6} \mu \mathrm{mHg}$ at room temperature, after degassing the samples.

The mesostructures were confirmed with a high-flux synchrotron SAXS instrument $(E=10.5199 \mathrm{keV}, \lambda=1.1785$ $\AA$ ) equipped with a $\mathrm{Si}(111)$ double crystal monochromator of $3 \mathrm{C}$ and $4 \mathrm{C}$ beamlines in Pohang Accelerator Laboratory (PAL) in POSTECH.

Pore characterization was performed by using nitrogen adsorption-desorption isotherms obtained by a Micromeritics 2420 analyzer at $-196^{\circ} \mathrm{C}$. All the samples were degassed at $300{ }^{\circ} \mathrm{C}$ under a vacuum below $30 \mu \mathrm{mHg}$ before the analysis. The BET specific surface area $\left(S_{\mathrm{BET}}\right)$ was obtained from the adsorption isotherm in the relative pressure $\left(P / P_{0}\right)$ range of 0.04-0.2. The total pore volume $\left(V_{\mathrm{t}}\right)$ was taken from the amount adsorbed at a relative pressure of 0.99 . The PSD curves were calculated from the adsorption isotherm using the Kruk-Jaroniec-Sayari (KJS) method. ${ }^{56}$

4.5. Synthesis of Poly(arylene ether sulfone) Multiblock Copolymer. On the basis of our previous report, ${ }^{9,57}$ SPAES multiblock copolymers were synthesized by nucleophilic aromatic substitution reactions between hydroxyl- and fluorine-terminated oligomers, as shown in Figure 6. A typical synthetic procedure of fluorine-terminated hydrophilic oligomers was performed as follows: HQs (1.66 g, 7.3 $\mathrm{mmol})$, DSFDPS (3.67 g, $8.0 \mathrm{mmol})$, DMSO $(16 \mathrm{~mL})$, and $\mathrm{K}_{2} \mathrm{CO}_{3}(1.21 \mathrm{~g}, 8.7 \mathrm{mmol})$ were added to a three-neck $100 \mathrm{~mL}$ flask. The reaction temperature was slowly increased to 120 ${ }^{\circ} \mathrm{C}$. After completing the reaction, celite was poured into the reacted solution to remove the catalyst, and the solution was filtered. The solution was poured dropwise into $1 \mathrm{~L}$ of hot methanol to remove the unreacted monomers and then filtered. The obtained oligomers were dried in a vacuum at 80 ${ }^{\circ} \mathrm{C}$ for at least $24 \mathrm{~h}$. The hydroxyl-hydrophobic oligomer was synthesized using the same procedure as for the hydrophilic oligomer, except that sulfonated monomers were replaced with 4,4'-dihydroxy biphenyl and FDPS.

For the synthesis of multiblock copolymers, the hydroxylterminated hydrophobic oligomer dissolved in DMAc was mixed with a DMSO solution containing the fluorineterminated hydrophilic oligomer. The step-growth coupling reaction was conducted for $12 \mathrm{~h}$ at $130{ }^{\circ} \mathrm{C}$. After the polymerization reaction, excess DMSO was added to decrease the viscosity, and then the polymer solution was added dropwise into deionized water. The final multiblock copolymer sample was obtained after filtering and drying in a vacuum oven at $100{ }^{\circ} \mathrm{C}$ overnight. The number- and weight-average molecular weights were determined as 100 and $270 \mathrm{kDa}$, respectively, from GPC (YL9100, Younglin Co, Korea) analysis with a UV detector based on the molecular weight relative to a polystyrene standard. N,N-Dimethylacetamide (DMAc) with $0.05 \mathrm{M} \mathrm{LiBr}$ was used as the eluent, and KF805L (Shodex) was used as the column.

4.6. Preparation of a Polymer/Mesoporous Material Composite Membrane. A pristine SPAES membrane was prepared using the facile solvent casting method. The salt form of SPAES was dissolved in DMSO and filtered through a 0.45 $\mu \mathrm{m}$ filter before casting. The 7 wt $\%$ SPAES solution was poured on a clean glass dish and dried at $80{ }^{\circ} \mathrm{C}$ for $24 \mathrm{~h}$. The membrane was changed to the acid form by boiling in a $3 \mathrm{M}$ $\mathrm{HCl}$ solution for $8 \mathrm{~h}$, which was repeated twice, followed by washing with deionized water several times. Finally, a transparent, flexible film was obtained. IEC was obtained by the titration method using a $0.01 \mathrm{M} \mathrm{NaOH}$ solution. This value is similar to that calculated from the ${ }^{1} \mathrm{H}$ NMR spectrum.

Before the composite membrane preparation, the surface of HCS30-HR and HCS50-HR ceria-silica samples was modified 
with THSPSA by the post-grafting method. To block the attack by the radicals, we selected HCS30-HR and HCS50-HR because they contain large amounts of reduced ceria. In addition, THSPSA-containing sulfonic acid was attached chemically on the surface of mesoporous samples to maintain proton conductivity. In a typical preparation of modified sHCS30-HR and sHCS50-HR samples, $0.5 \mathrm{~g}$ of HCS30-HR and HCS50-HR samples and $0.3 \mathrm{~mL}$ of THSPSA dissolved in $25 \mathrm{~mL}$ of toluene were treated at $90{ }^{\circ} \mathrm{C}$ for $24 \mathrm{~h}$. To form the composite membrane, mesoporous ceria-silica particles were ball-milled to obtain a powder pulverized into very small particles. Mesoporous ceria-silica was dispersed in the SPAES solution in DMSO (10 wt \%). The composite membranes with a Ce-doped mesoporous powder sample were prepared using a similar solvent casting method. The concentration of mesoporous ceria-silica was adjusted to be $2.5 \mathrm{wt} \%$ of the weight of the SPAES multiblock copolymer.

4.7. Measurement of the Antioxidant Property: Hydrogen Peroxide Exposure in Water Vapor. The oxidative stability was tested by exposing composite membranes to hydrogen peroxide vapor to imitate fuel cell operating conditions. ${ }^{19}$ Typically, $2 \times 2 \mathrm{~cm}^{2}$ membrane samples were held in a specially designed chamber at $120^{\circ} \mathrm{C}$ for $36 \mathrm{~h}$ at $\mathrm{RH}=10 \%$. Hydrogen peroxide vapor, generated by heating a reservoir containing 10 wt \% aqueous hydrogen peroxide and deionized water, was introduced into the chamber using ultrapure nitrogen gas as a carrier. After the test, membranes were washed with deionized water several times and dried at room temperature. The membrane was dissolved in $\mathrm{N}, \mathrm{N}$-dimethylformamide (DMF) to obtain a solution for GPC analysis. Mesoporous silica particles and impurities were removed by filtration through a $0.2 \mu \mathrm{m}$ syringe filter, and the filtrate was analyzed.

The change in the number- and weight-average molecular weight $\left(M_{\mathrm{n}}\right.$ and $\left.M_{\mathrm{w}}\right)$ before and after the test was analyzed by GPC measurements. GPC was carried out with a YL-Clarity data system (Young Lin Instrument Co., Ltd.) with a Shodex KF-805L column. High-performance liquid chromatography (HPLC)-grade DMF was used as the eluent with $0.05 \mathrm{M} \mathrm{LiBr}$ at a flow rate of $0.1 \mathrm{~mL} / \mathrm{min}$. Polystyrene standards were used for calibration.

4.8. Measurement of Proton Conductivity. The proton conductivity $(\sigma)$ of the composite membranes was measured using a BekkTech conductivity cell system equipped with a Solartron 1260 impedance/gain-phase analyzer and a Solartron 1287 electrochemical interface with a four-probe-type electrode cell. The RH was controlled from 90 to $20 \%$ at 80 ${ }^{\circ} \mathrm{C}$. The conductivity data were obtained after at least $2 \mathrm{~h}$ equilibrium in each humidity region. The $\sigma$ values were calculated using eq 1

$$
\sigma=D /(L \times B \times R)
$$

where $D$ is the distance between the reference and the electrode, $L$ is the length of the membrane, $B$ is the thickness of the membrane, and $R$ is the measured impedance value.

\section{ASSOCIATED CONTENT}

\section{SI Supporting Information}

The Supporting Information is available free of charge at https://pubs.acs.org/doi/10.1021/acsomega.1c03615.

Weight and ICP-AES analysis before and after the Fenton test; variation in the XPS spectra of the CCS30,
CCS30-HR, HCS30, HCS30-HR, HCS50, HCS50-HR, CM4, and CM4-HR sample before and after the Fenton test; variation in the nitrogen adsorption-desorption isotherm before and after the Fenton test for 12 and 120 h for CCS30, CCS30-HR, HCS30, HCS30-HR, HCS50, HCS50-HR, CM4, and CM4-HR; and variation in the pore size distribution before and after the Fenton test for 12 and 120 h for CCS30, CCS30-HR, HCS30, HCS30HR, HCS50, HCS50-HR, CM4, and CM4-HR (PDF)

\section{AUTHOR INFORMATION}

\section{Corresponding Authors}

Eun-Bum Cho - Department of Fine Chemistry, Seoul National University of Science and Technology, Seoul 01811, Republic of Korea; (1) orcid.org/0000-0002-4169-0189; Phone: +82-2-970-6729; Email: echo@seoultech.ac.kr

Byungchan Bae - Fuel Cell Laboratory, Korea Institute of Energy Research, Daejeon 34129, Republic of Korea; Department of Renewable Energy Engineering, University of Science and Technology (UST), Daejeon 34113, Republic of Korea; orcid.org/0000-0002-4783-8594; Phone: +8242-860-3586; Email: bcbae@kier.re.kr

\section{Authors}

Joonseok Kim - Department of Fine Chemistry, Seoul National University of Science and Technology, Seoul 01811, Republic of Korea

Hyejin Lee - Fuel Cell Laboratory, Korea Institute of Energy Research, Daejeon 34129, Republic of Korea

Complete contact information is available at:

https://pubs.acs.org/10.1021/acsomega.1c03615

\section{Author Contributions}

J.K. and H.L. contributed equally to this work.

\section{Notes}

The authors declare no competing financial interest.

\section{ACKNOWLEDGMENTS}

E.-B.C. acknowledges the support of the National Research Foundation of Korea (NRF-2020R1A2C1015117). Experiments at PLS-II were supported in part by MSICT and POSTECH. B.B. acknowledges support by Korea Institute of Energy Technology Evaluation and Planning (KETEP) grant (20203020030010) funded by the Korea government(MOTIE).

\section{REFERENCES}

(1) Hickner, M. A.; Ghassemi, H.; Kim, Y. S.; Einsla, B. R.; McGrath, J. E. Alternative Polymer Systems for Proton Exchange Membranes (PEMs). Chem. Rev. 2004, 104, 4587-4612.

(2) Kerres, J. A. Design Concepts for Aromatic Ionomers and Ionomer Membranes to be Applied to Fuel Cells and Electrolysis. Polym. Rev. 2015, 55, 273-306.

(3) Zhang, H.; Shen, P. K. Recent Development of Polymer Electrolyte Membranes for Fuel Cells. Chem. Rev. 2012, 112, 27802832.

(4) Rowlett, J. R.; Chen, Y.; Shaver, A. T.; Fahs, G. B.; Sundell, B. J.; Li, Q.; Seung Kim, Y.; Zelenay, P.; Moore, R. B.; Mecham, S.; McGrath, J. E. Multiblock Copolymers Based upon Increased Hydrophobicity Bisphenol A Moieties for Proton Exchange Membranes. J. Electrochem. Soc. 2014, 161, F535-F543.

(5) Weiber, E. A.; Takamuku, S.; Jannasch, P. Highly Proton Conducting Electrolyte Membranes Based on Poly(arylene sulfone)s 
with Tetrasulfonated Segments. Macromolecules 2013, 46, 34763485.

(6) Titvinidze, G.; Kreuer, K.-D.; Schuster, M.; de Araujo, C. C.; Melchior, J. P.; Meyer, W. H. Proton Conducting Phase-Separated Multiblock Copolymers with Sulfonated Poly(phenylene sulfone) Blocks for Electrochemical Applications: Preparation, Morphology, Hydration Behavior, and Transport. Adv. Funct. Mater. 2012, 22, 4456-4470.

(7) Miyake, J.; Mochizuki, T.; Miyatake, K. Effect of the Hydrophilic Component in Aromatic Ionomers: Simple Structure Provides Improved Properties as Fuel Cell Membranes. ACS Macro Lett. 2015, 4, 750-754.

(8) Lee, J. Y.; Yu, D. M.; Kim, T.-H.; Yoon, S. J.; Hong, Y. T. Multiblock copolymers based on poly(p-phenylene)s with excellent durability and fuel cell performance. J. Membr. Sci. 2015, 492, 209219.

(9) Lee, S.; Ann, J.; Lee, H.; Kim, J.-H.; Kim, C.-S.; Yang, T.-H.; Bae, B. Synthesis and characterization of crosslink-free highly sulfonated multi-block poly(arylene ether sulfone) multi-block membranes for fuel cells. J. Mater. Chem. A 2015, 3, 1833-1836.

(10) Shin, D. W.; Guiver, M. D.; Lee, Y. M. Hydrocarbon-Based Polymer Electrolyte Membranes: Importance of Morphology on Ion Transport and Membrane Stability. Chem. Rev. 2017, 117, 47594805.

(11) Uegaki, R.; Akiyama, Y.; Tojo, S.; Honda, Y.; Nishijima, S. Radical-induced degradation mechanism of perfluorinated polymer electrolyte membrane. J. Power Sources 2011, 196, 9856-9861.

(12) Wu, J.; Yuan, X. Z.; Martin, J. J.; Wang, H.; Zhang, J.; Shen, J.; Wu, S.; Merida, W. A review of PEM fuel cell durability: Degradation mechanisms and mitigation strategies. J. Power Sources 2008, 184, 104-119.

(13) Holmes, T.; Skalski, T. J. G.; Adamski, M.; Holdcroft, S. Stability of Hydrocarbon Fuel Cell Membranes: Reaction of Hydroxyl Radicals with Sulfonated Phenylated Polyphenylenes. Chem. Mater. 2019, 31, 1441-1449.

(14) Yu, T. H.; Sha, Y.; Liu, W.-G.; Merinov, B. V.; Shirvanian, P.; Goddard, W. A. Mechanism for Degradation of Nafion in PEM Fuel Cells from Quantum Mechanics Calculations. J. Am. Chem. Soc. 2011, 133, 19857-19863.

(15) Collier, A.; Wang, H.; Ziyuan, X.; Zhang, J.; Wilkinson, D. Degradation of polymer electrolyte membranes. Int. J. Hydrogen Energy 2006, 31, 1838-1854.

(16) Andersen, S. M.; Nørgaard, C. F.; Larsen, M. J.; Skou, E. Tin Dioxide as an Effective Antioxidant for Proton Exchange Membrane Fuel Cells. J. Power Sources 2015, 273, 158-161.

(17) Endoh, E.; Terazono, S.; Widjaja, H.; Takimoto, Y. Degradation Study of MEA for PEMFCs under Low Humidity Conditions. Electrochem. Solid-State Lett. 2004, 7, A209-A211.

(18) Endoh, E. Development of Highly Durable PFSA Membrane and MEA for PEMFC Under High Temperature and Low Humidity Conditions. ECS Trans. 2008, 16, 1229-1240.

(19) Lee, H.; Han, M.; Choi, Y.-W.; Bae, B. Hydrocarbon-based polymer electrolyte cerium composite membranes for improved proton exchange membrane fuel cell durability. J. Power Sources 2015, 295, 221-227.

(20) Parnian, M. J.; Rowshanzamir, S.; Prasad, A. K.; Advani, S. G. Effect of ceria loading on performance and durability of sulfonated poly (ether ketone) nanocomposite membranes for proton exchange membrane fuel cell applications. J. Membr. Sci. 2018, 565, 342-357.

(21) Shin, D.; Han, M.; Shul, Y.-G.; Lee, H.; Bae, B. Analysis of cerium-composite polymer-electrolyte membranes during and after accelerated oxidative-stability test. J. Power Sources 2018, 378, 468474.

(22) Park, S.; Lee, H.; Shin, S.-H.; Kim, N.; Shin, D.; Bae, B. Increasing the Durability of Polymer Electrolyte Membranes Using Organic Additives. ACS Omega 2018, 3, 11262-11269.

(23) Shin, S.-H.; Kodir, A.; Shin, D.; Park, S.-H.; Bae, B. Perfluorinated composite membranes with organic antioxidants for chemically durable fuel cells. Electrochim. Acta 2019, 298, 901-909.
(24) Chen, J.; Patil, S.; Seal, S.; McGinnis, J. F. Rare earth nanoparticles prevent retinal degeneration induced by intracellular peroxides. Nat. Nanotechnol. 2006, 1, 142-150.

(25) Tarnuzzer, R. W.; Colon, J.; Patil, S.; Seal, S. Vacancy Engineered Ceria Nanostructures for Protection from RadiationInduced Cellular Damage. Nano Lett. 2005, 5, 2573-2577.

(26) Das, M.; Patil, S.; Bhargava, N.; Kang, J.-F.; Riedel, L. M.; Seal, S.; Hickman, J. J. Auto-catalytic ceria nanoparticles offer neuroprotection to adult rat spinal cord neurons. Biomaterials 2007, 28, $1918-1925$.

(27) Yu, L.; Lu, Y.; Man, N.; Yu, S.-H.; Wen, L.-P. Rare Earth Oxide Nanocrystals Induce Autophagy in HeLa Cells. Small 2009, 5, 27842787.

(28) Hirst, S. M.; Karakoti, A. S.; Tyler, R. D.; Sriranganathan, N.; Seal, S.; Reilly, C. M. Anti-inflammatory Properties of Cerium Oxide Nanoparticles. Small 2009, 5, 2848-2856.

(29) Dowding, J. M.; Dosani, T.; Kumar, A.; Seal, S.; Self, W. T. Cerium oxide nanoparticles scavenge nitric oxide radical (NO). Chem. Commun. 2012, 48, 4896-4898.

(30) Ferraro, D.; Tredici, I. G.; Ghigna, P.; Castillio-Michel, H.; Falqui, A.; Di Benedetto, C.; Alberti, G.; Ricci, V.; AnselmiTamburini, U.; Sommi, P. Dependence of the $\mathrm{Ce}($ iii)/Ce(iv) ratio on intracellular localization in ceria nanoparticles internalized by human cells. Nanoscale 2017, 9, 1527-1538.

(31) Kwon, H. J.; Kim, D.; Seo, K.; Kim, Y. G.; Han, S. I.; Kang, T.; Soh, M.; Hyeon, T. Ceria Nanoparticle Systems for Selective Scavenging of Mitochondrial, Intracellular, and Extracellular Reactive Oxygen Species in Parkinson's Disease. Angew. Chem., Int. Ed. 2018, 57, 9408-9412.

(32) Regoli, F.; Winston, G. W. Quantification of total oxidant scavenging capacity of antioxidants for peroxynitrite, peroxyl radicals, and hydroxyl radicals. Toxicol. Appl. Pharmacol. 1999, 156, 96-105.

(33) Zhang, H.-Y. Investigation on the effectiveness of HOMO to characterize antioxidant activity. J. Am. Oil Chem. Soc. 1999, 76, $1109-1110$.

(34) Nosaka, Y.; Nosaka, A. Y. Generation and Detection of Reactive Oxygen Species in Photocatalysis. Chem. Rev. 2017, 117, 11302-11336.

(35) Park, J.; Kim, D. Effect of cerium/18-crown-6-ether coordination complex $\mathrm{OH}$ quencher on the properties of sulfonated poly(ether ketone) fuel cell electrolyte membranes. J. Membr. Sci. 2014, 469, 238-244.

(36) Trogadas, P.; Parrondo, J.; Ramani, V. Degradation Mitigation in Polymer Electrolyte Membranes Using Cerium Oxide as a Regenerative Free-Radical Scavenger. Electrochem. Solid-State Lett. 2008, 11, B113.

(37) Pearman, B. P.; Mohajeri, N.; Slattery, D. K.; Hampton, M. D.; Seal, S.; Cullen, D. A. The chemical behavior and degradation mitigation effect of cerium oxide nanoparticles in perfluorosulfonic acid polymer electrolyte membranes. Polym. Degrad. Stab. 2013, 98, $1766-1772$.

(38) Xue, Y.; Luan, Q.; Yang, D.; Yao, X.; Zhou, K. Direct Evidence for Hydroxyl Radical Scavenging Activity of Cerium Oxide Nanoparticles. J. Phys. Chem. C 2011, 115, 4433-4438.

(39) Kresge, C. T.; Leonowicz, M. E.; Roth, W. J.; Vartuli, J. C.; Beck, J. S. Ordered mesoporous molecular sieves synthesized by a liquid-crystal template mechanism. Nature 1992, 359, 710-712.

(40) Trewyn, B. G.; Slowing, I. I.; Giri, S.; Chen, H.-T.; Lin, V. S.-Y. Synthesis and Functionalization of a Mesoporous Silica Nanoparticle Based on the Sol-Gel Process and Applications in Controlled Release. Acc. Chem. Res. 2007, 40, 846-853.

(41) Shephard, D. S.; Zhou, W.; Maschmeyer, T.; Matters, J. M.; Roper, C. L.; Parsons, S.; Johnson, B. F. G.; Duer, M. J. Site-Directed Surface Derivatization of MCM-41: Use of High-Resolution Transmission Electron Microscopy and Molecular Recognition for Determining the Position of Functionality within Mesoporous Materials. Angew. Chem., Int. Ed. 1998, 37, 2719-2723.

(42) de Juan, F.; Ruiz-Hitzky, E. Selective Functionalization of Mesoporous Silica. Adv. Mater. 2000, 12, 430-432. 
(43) Cheng, K.; Landry, C. C. Diffusion-Based Deprotection in Mesoporous Materials: A Strategy for Differential Functionalization of Porous Silica Particles. J. Am. Chem. Soc. 2007, 129, 9674-9685.

(44) Zhao, D.; Budhi, S.; Rodriguez, A.; Koodali, R. T. Rapid and facile synthesis of Ti-MCM-48 mesoporous material and the photocatalytic performance for hydrogen evolution. Int. J. Hydrogen Energy 2010, 35, 5276-5283.

(45) Liu, S.; Wang, H. P. Photocatalytic generation of hydrogen on Zr-MCM-41. Int. J. Hydrogen Energy 2002, 27, 859-862.

(46) Shen, S.; Guo, L. Hydrothermal synthesis, characterization, and photocatalytic performances of $\mathrm{Cr}$ incorporated, and $\mathrm{Cr}$ and $\mathrm{Ti}$ coincorporated MCM-41 as visible light photocatalysts for water splitting. Catal. Today 2007, 129, 414-420.

(47) Sayari, A. Catalysis by Crystalline Mesoporous Molecular Sieves. Chem. Mater. 1996, 8, 1840-1852.

(48) Peng, R.; Zhao, D.; Dimitrijevic, N. M.; Rajh, T.; Koodali, R. T. Room Temperature Synthesis of Ti-MCM-48 and Ti-MCM-41 Mesoporous Materials and Their Performance on Photocatalytic Splitting of Water. J. Phys. Chem. C 2012, 116, 1605-1613.

(49) Zhao, D.; Rodriguez, A.; Dimitrijevic, N. M.; Rajh, T.; Koodali, R. T. Synthesis, Structural Characterization, and Photocatalytic Performance of Mesoporous W-MCM-48. J. Phys. Chem. C 2010, 114, 15728-15734.

(50) Cho, E.-B.; Yim, S.; Kim, D.; Jaroniec, M. Surfactant-assisted synthesis of mesoporous silica/ceria-silica composites with high cerium content under basic conditions. J. Mater. Chem. A 2013, 1, 12595-12605

(51) Pal, N.; Cho, E.-B.; Kim, D.; Gunathilake, C.; Jaroniec, M. Catalytic activity of CeIVO2/Ce2IIIO3-silica mesoporous composite materials for oxidation and esterification reactions. Chem. Eng. Sci. 2015, 262, 1116-1125.

(52) Kim, J.; Chung, K.; Lee, H.; Bae, B.; Cho, E.-B. Mesoporous ceria-silica/poly(arylene ether sulfone) composite membranes for durability of fuel cell electrolyte membrane. Microporous Mesoporous Mater. 2016, 236, 292-300.

(53) Mack, F.; Aniol, K.; Ellwein, C.; Kerres, J.; Zeis, R. Novel phosphoric acid-doped PBI-blends as membranes for high-temperature PEM fuel cells. J. Mater. Chem. A 2015, 3, 10864-10874.

(54) Gasa, J. V.; Weiss, R. A.; Shaw, M. T. Ionic crosslinking of ionomer polymer electrolyte membranes using barium cations. J. Membr. Sci. 2007, 304, 173-180.

(55) Pal, N.; Cho, E.-B.; Kim, D.; Jaroniec, M. Mn-Doped Ordered Mesoporous Ceria-Silica Composites and Their Catalytic Properties toward Biofuel Production. J. Phys. Chem. C 2014, 118, 1589215901.

(56) Jaroniec, M.; Solovyov, L. A. Improvement of the KrukJaroniec-Sayari Method for Pore Size Analysis of Ordered Silicas with Cylindrical Mesopores. Langmuir 2006, 22, 6757-6760.

(57) Yuk, J.; Lee, S.; Nugraha, A. F.; Lee, H.; Park, S.-H.; Yim, S.-D.; Bae, B. Synthesis and characterization of multi-block poly(arylene ether sulfone) membranes with highly sulfonated blocks for use in polymer electrolyte membrane fuel cells. J. Membr. Sci. 2016, 518, 50-59. 